\title{
Condições Higiênico-Sanitárias Dos Estabelecimentos Produtores de Alimentos no Município de Itaqui (RS)
}

\author{
Jassana Moreira Floriano (I), Marcelo Valle Garcia (II), Priscila \\ Schwarzer (I), Narlice Marques (I), Joice Trindade Silveira (I), Carla \\ Cristina Bauermann Brasil (II) \\ (I) UNIPAMPA - Universidade Federal do Pampa (Campus Itaqui - Rua Luiz Joaquim de Sá \\ Britt, s/n - Bairro Promorar - Itaqui ), (II) UFSM - Universidade Federal de Santa Maria (Av. \\ Roraima no 1000 Cidade Universitária Bairro Camobi Santa Maria - RS)
}

\section{Resumo}

Com o crescimento dos serviços de alimentação para atender a demanda populacional e o aumento do número de casos de doenças transmitidas por alimentos, surge a necessidade da adequação das boas práticas de manipulação dos alimentos. Objetivou-se com este trabalho avaliar as condições higiênico-sanitárias do processo produtivo de refeições em estabelecimentos produtores de alimentos localizados no município de Itaqui (RS). Trata-se de um estudo exploratório descritivo, realizado em 24 estabelecimentos, sendo estes divididos entre dez restaurantes comerciais, sete lanchonetes, cinco padarias e dois hotéis. Foram realizadas visitas in loco para aplicar o roteiro de inspeção que foi realizado por observação direta e análise documental. A lista de verificação utilizada foi adaptada da Resolução de Diretoria Colegiada (RDC) $n^{\circ}$. 216, de 15 de setembro de 2004, a fim de avaliar as condições higiênico-sanitárias e identificar não conformidades que possam interferir na qualidade dos alimentos servidos. Após a aplicação da lista de verificação, os estabelecimentos foram classificados utilizando a seguinte faixa de pontuação: grupo 1 (bom) entre $76-100 \%$, grupo 2 (regular) entre $51-75 \%$ e grupo 3 (deficiente) entre 0 $50 \%$ de adequação. Os resultados da média de adequação foram identificados de acordo com o tipo de estabelecimento, em que, os restaurantes comerciais apresentaram $46,06 \%$ de adequação, as padarias

\footnotetext{
Referência:

Jassana Moreira Floriano, Marcelo Valle Garcia, Priscila Schwarzer, Narlice Marques, Joice Trindade Silveira, Carla Cristina Bauermann Brasil. Condições Higiênico-Sanitárias Dos Estabelecimentos Produtores de Alimentos no Município de Itaqui (Rs). In: Anais do $12^{\circ}$ Congresso Latinoamericano de Microbiologia e Higiene de Alimentos MICROAL 2014 [= Blucher Food Science Proceedings, num.1, vol.1]. São Paulo: Editora Blucher, 2014. DOI 10.5151/foodsci-microal-214
} 
$39,09 \%$, as lanchonetes $34,16 \%$ e os hotéis $32,56 \%$ de adequação conforme a legislação sanitária vigente. Todos os estabelecimentos foram classificados no Grupo 3, demonstrando com isto a fragilidade destes em relação a segurança dos alimentos produzidos e comercializados. Os itens que obtiveram menor percentual de adequação estavam relacionados à existência de responsáveis técnicos e documentações. Através destes resultados, verifica-se que a adequação de diferentes tipos de estabelecimentos produtores de alimentos de acordo com a RDC $\mathrm{n}^{\circ}$. 216/2004 ainda não é uma realidade no Brasil, mesmo passados 10 anos da promulgação da legislação sanitária.

Palavras-Chave: Lanchonete, Adequação, Legislação Agência de Fomento: 